\title{
Leukemia mortality in children from Latin America: trends and predictions to 2030
}

\author{
J. Smith Torres-Roman ${ }^{1,2,3^{*}}$ (D), Bryan Valcarce ${ }^{3,4}$, Pedro Guerra-Canchari ${ }^{3,5}$, Camila Alves Dos Santos ${ }^{3,6}$, \\ Isabelle Ribeiro Barbosa, ${ }^{3,6}$, Carlo La Vecchia ${ }^{7}$, Katherine A. McGlynn ${ }^{8}$ and Dyego Leandro Bezerra de Souza, $3,6,9$
}

\begin{abstract}
Background: Reports suggest that Latin American and Caribbean (LAC) countries have not reduced leukemia mortality compared to high-income countries. However, updated trends remain largely unknown in the region. Given that leukemia is the leading cause of cancer-related death in LAC children, we evaluated mortality trends in children (0-14y) from 15 LAC countries for the period 2000-2017 and predicted mortality to 2030.

Methods: We retrieved cancer mortality data using the World Health Organization Mortality Database. Mortality rates (standardized to the world standard SEGI population) were analyzed for 15 LAC countries. We evaluated the average mortality rates for the last 5 years (2013-2017). Joinpoint regression analysis was used to evaluate leukemia mortality trends and provide an estimated annual percent change (EAPC). Nordpred was utilized for the calculation of predictions until 2030.
\end{abstract}

Results: Between 2013 and 2017, the highest mortality rates were reported in Venezuela, Ecuador, Nicaragua, Mexico, and Peru. Upward mortality trends were reported in Nicaragua (EAPC by $2.9 \%$ in boys, and EAPC by $2.0 \%$ in girls), and Peru (EAPC by $1.4 \%$ in both sexes). Puerto Rico experienced large declines in mortality among both boys (EAPC by $-9.7 \%$ ), and girls (EAPC by $-6.0 \%$ ). Leukemia mortality will increase in Argentina, Ecuador, Guatemala, Panama, Peru, and Uruguay by 2030.

Conclusion: Leukemia mortality is predicted to increase in some LAC countries by 2030. Interventions to prevent this outcome should be tailor to reduce the socioeconomic inequalities and ensure universal healthcare coverage.

Keywords: Child, Leukemia, Mortality rate, Trends, epidemiology, Latin America

\section{Background}

Leukemia is a heterogeneous group of hematologic malignancies [1]. In 2018, GLOBOCAN reported nearly 65, 000 new cases (incidence rate of 3.4 per 100,000) and approximately 30,000 deaths (mortality rate of 1.5 per $100,000)$ in children under 15 of age worldwide $[2,3]$. Both incidence and mortality are higher in boys compared to girls $[1,3]$. In fact, GLOBOCAN reported that the incidence rate among boys was 3.8 per 100,000 and

\footnotetext{
* Correspondence: jstorresroman@gmail.com

'Universidad Científica del Sur, Lima, Peru

Universidad Católica Los Ángeles de Chimbote, Instituto de Investigación, Chimbote, Peru

Full list of author information is available at the end of the article
}

the mortality rate was 1.7 per 100,000 , whereas the incidence rate among girls was 2.9 per 100,000 and the mortality rate was 1.3 per 100,000 [3]. Regarding childhood leukemia, acute lymphoblastic leukemia $(80 \%)$ is the most common subtype, followed by acute myeloid leukemia (15\%), and other types of leukemia (5\%) [1, 4].

Over the last several years, many countries have experienced declining childhood leukemia mortality rates, principally due to the improvement of treatment regimens and supportive care [5-8]. For example, a study in the European children reported a decrease among boys mortality rates from 1.35 in 1997 to 0.85 in 2007 (37\%

C C The Author(s). 2020 Open Access This article is licensed under a Creative Commons Attribution 4.0 International License, which permits use, sharing, adaptation, distribution and reproduction in any medium or format, as long as you give appropriate credit to the original author(s) and the source, provide a link to the Creative Commons licence, and indicate if changes were made. The images or other third party material in this article are included in the article's Creative Commons licence, unless indicated otherwise in a credit line to the material. If material is not included in the article's Creative Commons licence and your intended use is not permitted by statutory regulation or exceeds the permitted use, you will need to obtain permission directly from the copyright holder. To view a copy of this licence, visit http://creativecommons.org/licenses/by/4.0/ The Creative Commons Public Domain Dedication waiver (http://creativecommons.org/publicdomain/zero/1.0/) applies to the data made available in this article, unless otherwise stated in a credit line to the data. 
reduction), whereas among girls declined from 1.07 in 1997 to 0.70 in 2007 (35\% reduction) [5].

Notwithstanding these improvements, leukemia remains the leading cause of cancer mortality in Latin American and the Caribbean (LAC) children, considered as a major public health challenge in this region $[9,10]$. For example, between 1980 and 2014, Mexico reported a rise of mortality rates of leukemia (19\% in boys and $21 \%$ in girls) [10]. The barriers to healthcare access, social disparities, and the lack of economic resources in LAC hamper the survival improvements seen in high-income countries [11, 12]. Other factors related to increased mortality include delayed diagnosis, treatment abandonment, lack of a proper supportive care, and a shortage of pediatric oncologists as well as nurses dedicated to pediatric oncology care $[13,14]$.

To our knowledge, few studies have attempted to provide a comprehensive population-based analysis of leukemia mortality trends in the LAC region [10]. Given the high mortality burden among LAC countries, it is important to perform updated analysis to identify and evaluate the current status of leukemia mortality for the future development of evidence-based health policies. Along this line, the use of cancer predictions provides further insight toward optimal decision making in public health and the correct planning and allocation of resources for health improvement. Therefore, we sought to identify mortality trends for leukemia in children from LAC countries between 2000 and 2017 and to predict mortality until 2030.

\section{Methods}

\section{Design and study setting}

A study of mortality trends was conducted based on data from the World Health Organization Mortality Database [15]. The countries that had data available for analysis between 2000 and 2017 included: Argentina, Brazil, Chile, Costa Rica, Cuba, Ecuador, Guatemala, Mexico, Nicaragua, Panama, Paraguay, Peru, Puerto Rico, Uruguay, and Venezuela (2000-2014). We included deaths due to leukemia (C91-C95) according to the International Statistical Classification of Diseases and Related Health Problems - 10th revision [16]. Population demographics (sex and age) were obtained for each country from the Pan American Health Organization [17], as previous studies in Latin America have done $[18,19]$.

\section{Data analysis}

Age-standardized mortality rates (ASMRs) were estimated using the direct method and the world standard SEGI population per 100,000 persons-years [20]. Leukemia mortality trends were analyzed for children aged 0 to 14 years, stratified in three age groups $(0-4,5-$ 9, and 10-14) between 2000 and 2017. We computed the average mortality rates for the last 5 years with the purpose of showing updated data for leukemia in LAC (Fig. 1). We also provided an estimate of overall leukemia mortality rates in the LAC for the year 2030.

Mortality trends analysis was carried out by Joinpoint regression, utilizing the Joinpoint Regression Program, version 4.6.0.0 (National Cancer Institute, Bethesda, Maryland, USA) [21]. The objective of the analysis was to identify the years where a significant change in the linear slope of the trend (on a log-scale) was detected over the study period. The method identified a maximum of three joinpoints. The final selected model provided the estimated annual percentage change (EAPC) based on the trend of each segment, using a $95 \%$ confidence interval. The significance levels utilized were based on the Monte Carlo permutation model and on the calculation of the annual percentage change of ratio, utilizing the logarithm of the ratio [22, 23].

Predictions were made for each period utilizing the age-period-cohort model from the Nordpred program (Cancer Registry of Norway, Oslo, Norway), using the R software program. Data were compiled in blocks of five years and the limit age group considered for analysis was the first with more than 10 cases for the combined period [24, 25]. This model allows the comparison of birth cohorts, calculated by the decrease in the age range by calendar period, which result in intervals for the years of birth of each 5-year cohort. The calculation can be represented by the following formula [25]:

$$
\mathrm{R}_{\mathrm{ap}}=\exp \left(\mathrm{A}_{\mathrm{a}}+\mathrm{D} \mathrm{p}+\mathrm{P}_{\mathrm{p}}+\mathrm{C}_{\mathrm{c}}\right)
$$

In this formula, $R_{a p}$ is the incidence ratio for the age group "a" in the "p" period; D is the common drift parameter (which is the linear average of increase in the observed period); $A_{a}$ is the age-related component for group "a"; $P_{p}$ represents the nonlinear component for the period " $\mathrm{p}$ "; and $\mathrm{C}_{\mathrm{c}}$ corresponds to the nonlinear component of cohort " $\mathrm{c}$ ".

The results of the predictions are presented for the total number of deaths observed and expected for each period by country (except for Venezuela due to information available only until 2014). For each period, adjusted mortality rates were calculated based on the world standard SEGI population for global comparisons, expressed per 100,000 persons-years. The predictions of the most recent linear trend for the last ten years was attenuated in the drift parameter of $25 \%$ in the second and $50 \%$ in third 5-year period prediction periods, and $75 \%$ from the fourth period [26]. The objective of this mathematical operation is to reduce the influence of the current trend on predictions. The proposed model is based on empirical comparisons from different methods of predictions [26]. 


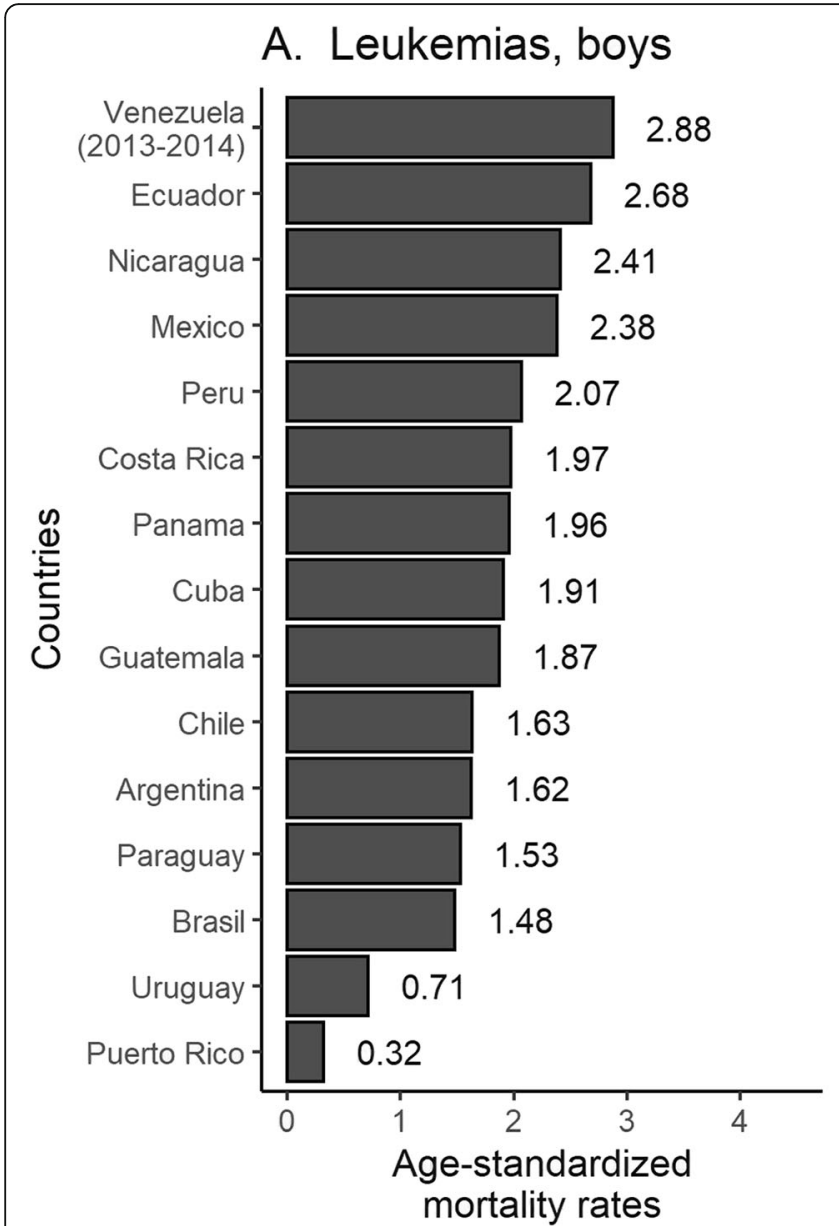

B. Leukemias, girls

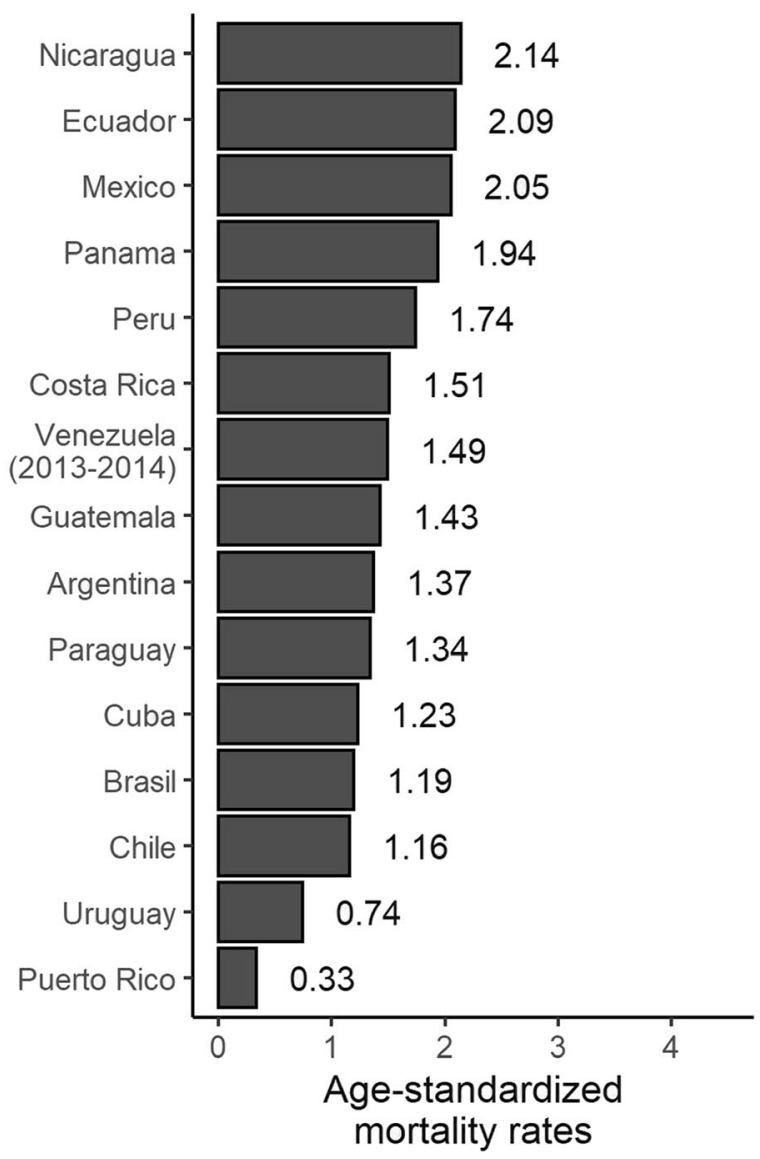

Fig. 1 Age-standardized leukemia mortality rates (world standard population) per 100,000 among boys and girls 0-14 years of age from 15 Latin American countries between 2013 and 2017

Annual changes were calculated for the number of predicted deaths in 2030 compared to the observed deaths in 2015, where the proportion of the change could occur in terms of changes in risks or demographics (size or structure of the population). These two components can be different from zero and can be either positive or negative in direction. The calculation can be expressed as [26].

$$
\begin{aligned}
\Delta \text { tot }=\Delta \text { risk }+\Delta \text { pop }= & (\text { Nfff }- \text { Noff }) \\
& +(\text { Noff }- \text { Nooo })
\end{aligned}
$$

Where $\Delta$ tot is the total change, $\Delta$ risk is the change in function of risk, $\Delta$ pop is the change in function of the population, Nooo is the number of observed cases, Nfff is the number of projected cases, and Noff is the number of expected cases when the mortality rates increase during the observed period.

\section{Ethical considerations}

This manuscript is based on administrative databases and does not use any personal identifiable information.

\section{Results}

Figure 1 shows the ASMRs per 100,000 person-years in children from 15 LAC countries between 2013 and 2017. Venezuela, Ecuador, Nicaragua, Mexico, and Peru reported the highest mortality rates in boys (above 2 deaths per 100,000 persons-years), while Nicaragua, Ecuador, and Mexico reported the highest mortality rates in girls (above 2 deaths per 100,000 persons-years). The lowest mortality rates were reported in Uruguay and Puerto Rico for both sexes (below 1 death per 100, 000 persons-years).

Figure 2 illustrates the percent changes between the periods 2000-2005 and 2012-2017 in LAC countries. Most countries reported decreases, mainly in boys. The greatest decreases were reported in Venezuela $(-60 \%$ in boys and $-55 \%$ girls), Puerto Rico (- $69 \%$ in boys and - 


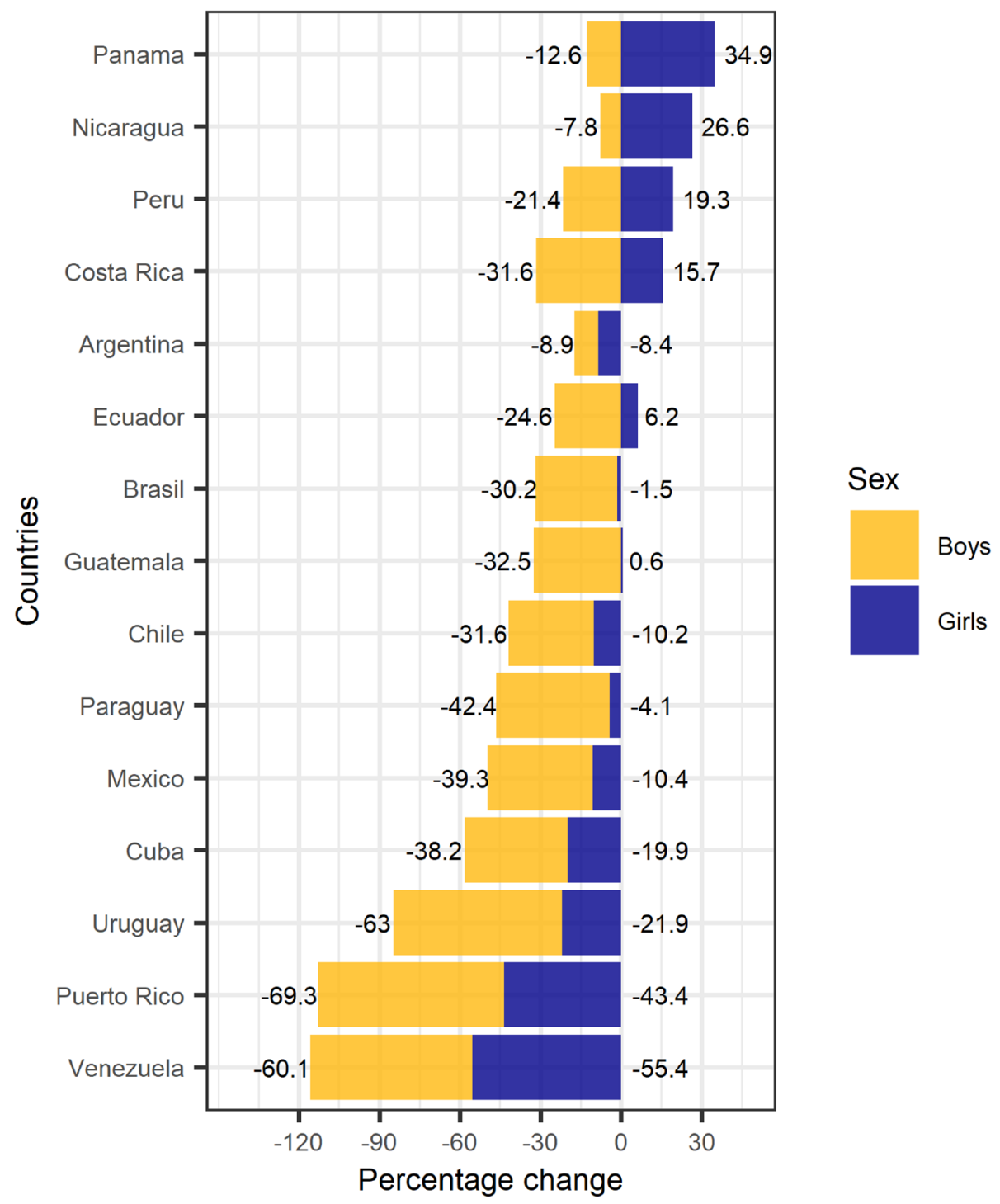

Fig. 2 Percent changes between the periods 2000-2005 and 2012-2017 in Latin American countries

$43 \%$ in girls), and Uruguay (-63\% in boys and $-22 \%$ in girls). Some differences by sex were reported in Panama, Nicaragua, Peru, Costa Rica, Ecuador, and Guatemala. For instance, Panama declined by $12.6 \%$ among boys, but increased by $34.9 \%$ among girls, Nicaragua declined by $7.8 \%$ among boys, but increased by $26.6 \%$ among girls, and Peru declined by $21.4 \%$ among boys, but increased 19.3\% among girls (See Supplementary 1).

In boys, Nicaragua (EAPC $=2.9,95 \%$ CI: $0.5,5.3, p<$ $0.05)$ and Peru (EAPC $=1.4,95 \%$ CI: $0.3,2.5, p<0.05)$ had significant upward trends in whole period, whereas Puerto Rico $(\mathrm{EAPC}=-14.8,95 \% \mathrm{CI}:-25.4,-2.8, p<$ 0.05 ) and Uruguay (EAPC $=-4.4,95 \% \mathrm{CI}:-7.3,-1.3$, $p<0.05)$ experienced downward trends. Whereas in girls, only Peru had an upward trend $(\mathrm{EAPC}=1.4,95 \%$ CI: $0.1,2.8, \mathrm{p}<0.05)$, while, three countries showed downward trends, Puerto Rico $(\mathrm{EAPC}=-8.8,95 \% \mathrm{CI}$ : $16.4,-0.5, \mathrm{p}<0.05)$ experienced the greatest reduction, followed by Uruguay (EAPC $=-7.4,95 \%$ CI: -14.7 , $0.3, \mathrm{p}<0.05)$ and Mexico $(\mathrm{EAPC}=-0.7,95 \% \mathrm{CI}:-1.3$, $-0.1, \mathrm{p}<0.05)$ (Fig. 3, Fig. 4, and Supplementary 2).

Table 1 shows the number of projected leukemia deaths in boys, age-standardized mortality rates and percentage change in deaths due to population and risk between 2015 and 2030. The forecast indicates that mortality rates will increase in Argentina, Brazil, Chile, Ecuador, Guatemala, Mexico, Peru, Puerto Rico, and Uruguay; and decline in Costa Rica, Cuba, Nicaragua, Panama, and Paraguay. The evaluation of change due to risk between 2015 and 2030, among boys, found a pronounced increase in Argentina (+21.8\%), Uruguay (+ $29.8 \%)$, and Ecuador $(+31.8 \%)$. The predicted total 


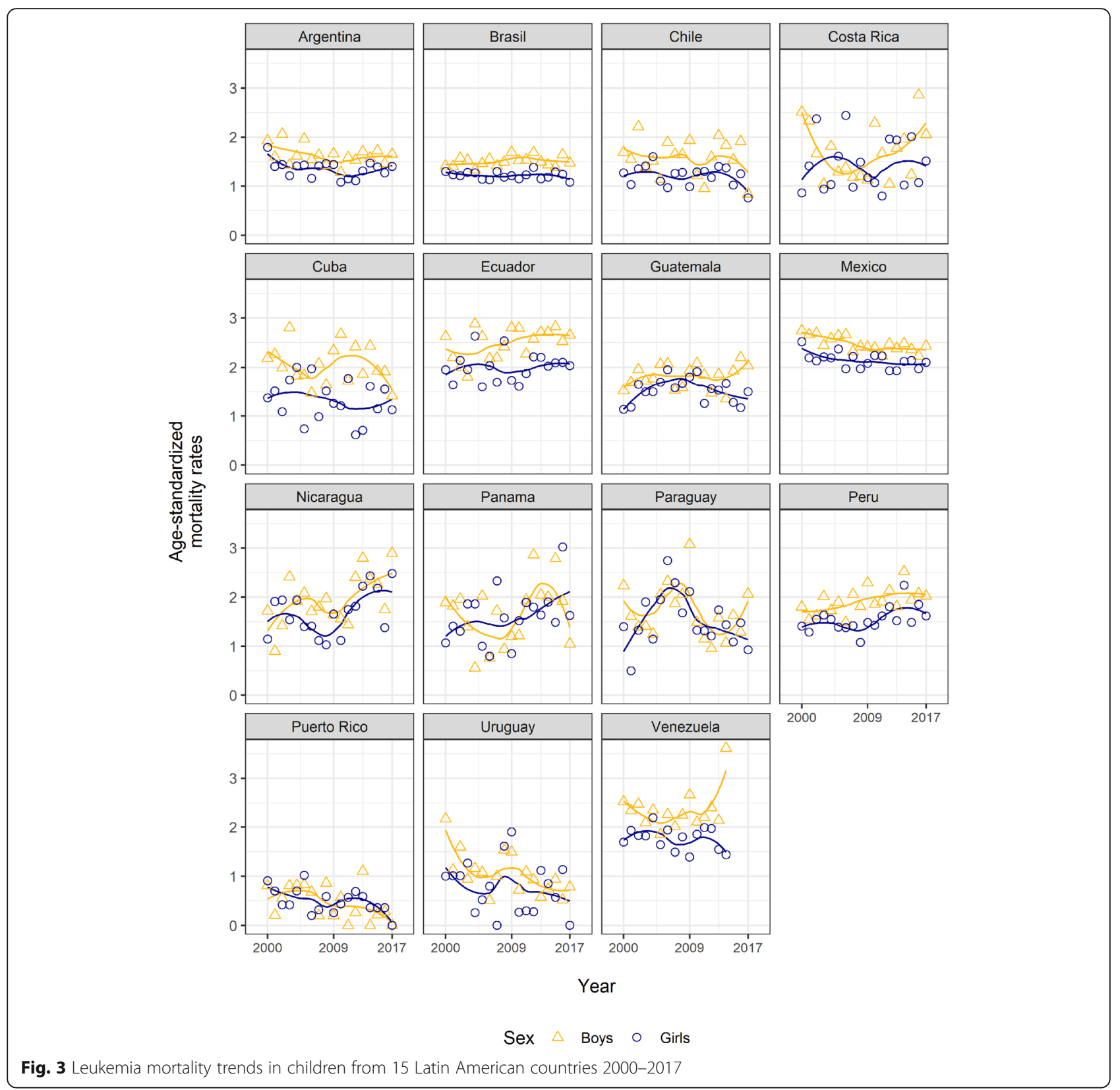

reduction in rates in Puerto Rico $(-56.7 \%)$ would be predominantly due to population change $(-58.7 \%)$, despite an increase in the risk of leukemia mortality (+ $2.1 \%)$. Ecuador is forecast to have an increase in population $(+5.8 \%)$ and risk of death $(+31.8 \%)$, resulting in an overall increase for leukemia mortality $(+37.6 \%)$.

Among girls, mortality rates will potentially increase in most LAC countries. In addition, there will be an increase in the risk of leukemia mortality in Argentina, Chile, Cuba, Ecuador, Nicaragua, Peru, Puerto Rico, and Uruguay which was the basis for the predicted increase among all the countries (except for a decline in Chile of 4.9\%). For Cuba, and Puerto Rico, there will a reduction in mortality resulting from changes in population structure and size, whereas in Brazil, Costa Rica, and Mexico there will be a reduction in mortality due to both population changes and a decrease in the risk of leukemia mortality (Table 2).

\section{Discussion}

This study provides a comprehensive population-based analysis of mortality trends for leukemia among children in 15 LAC countries. We found that Peru and Nicaragua had significant upward trends from 2000 to 2017, while most of the remaining countries showed little variation in mortality trends. Moreover, the analysis identified a 


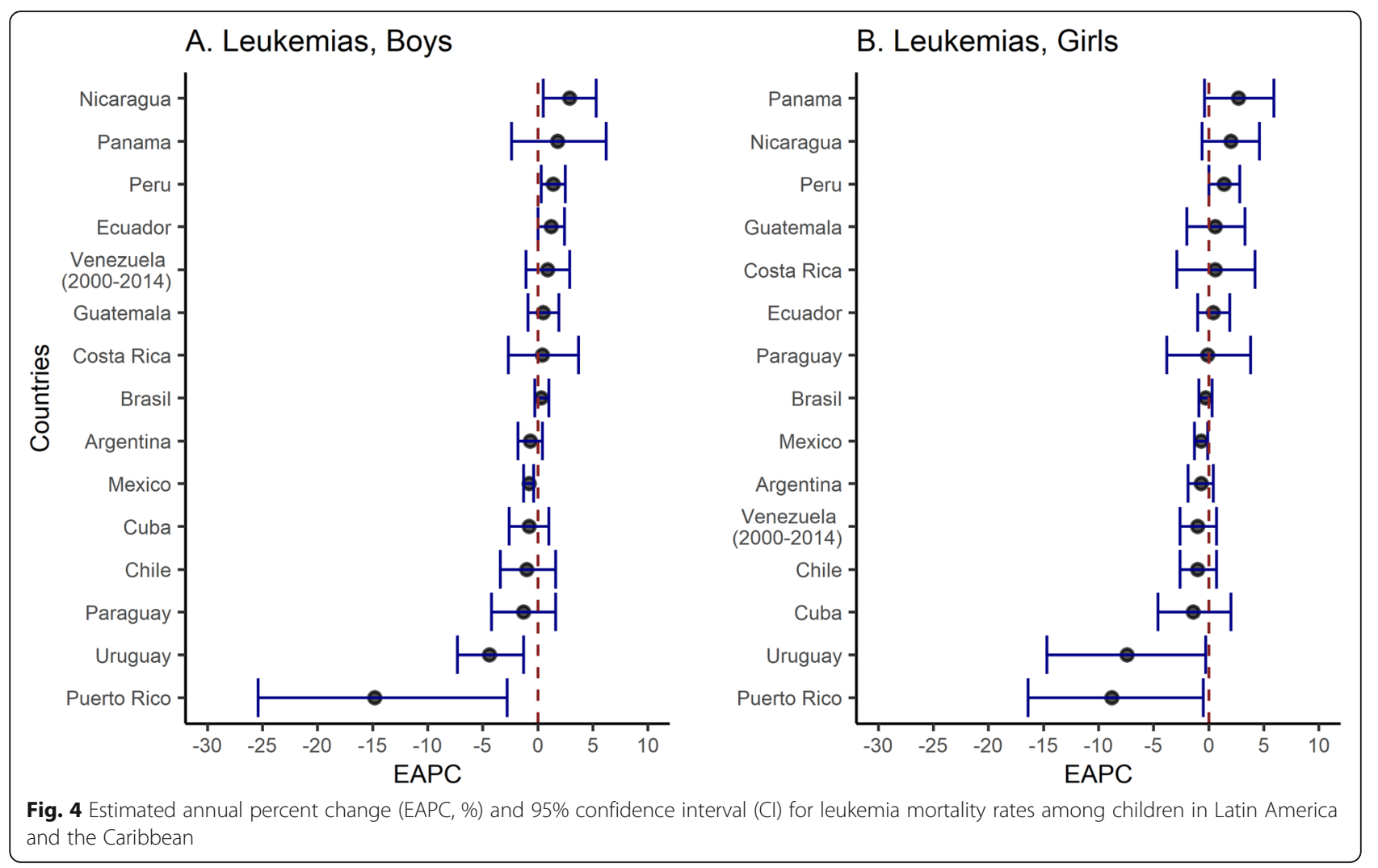

Table 1 Number of leukemia death in boys, age-standardized mortality rates and percentage change in cases due to population and risk, 2015 and 2030

\begin{tabular}{|c|c|c|c|c|c|c|c|c|c|}
\hline \multirow[t]{2}{*}{ Countries } & \multicolumn{2}{|c|}{ Population (per million) } & \multicolumn{2}{|c|}{ Number of deaths } & \multicolumn{2}{|c|}{ Age-standardized mortality rates } & \multirow{2}{*}{$\begin{array}{l}\text { Total } \\
\text { change } \\
(\%)\end{array}$} & \multirow{2}{*}{$\begin{array}{l}\text { Change } \\
\text { due to } \\
\text { population } \\
\text { (\%) }\end{array}$} & \multirow{2}{*}{$\begin{array}{l}\text { Change } \\
\text { due to } \\
\text { risk (\%) }\end{array}$} \\
\hline & 2015 & 2030 & 2015 & 2030 & 2015 & 2030 & & & \\
\hline Argentina & 5.5 & 5.6 & 450 & 554 & 1.61 & 1.91 & 23.0 & 1.2 & 21.8 \\
\hline Brazil & 24.4 & 20.9 & 1813 & 1645 & 1.48 & 1.57 & -9.3 & -14.3 & 5.0 \\
\hline Chile & 1.8 & 1.6 & 153 & 146 & 1.64 & 1.69 & -4.6 & -9.0 & 4.4 \\
\hline Costa Rica & 0.5 & 0.5 & 55 & 43 & 1.97 & 1.70 & -21.1 & -8.0 & -13.1 \\
\hline Cuba & 1.0 & 0.8 & 87 & 65 & 1.91 & 1.70 & -25.9 & -15.3 & -10.6 \\
\hline Ecuador & 2.3 & 2.5 & 326 & 449 & 2.68 & 3.44 & 37.6 & 5.8 & 31.8 \\
\hline Guatemala & 3.0 & 3.1 & 288 & 313 & 1.87 & 1.93 & 8.8 & 5.2 & 3.5 \\
\hline Mexico & 17.8 & 16.2 & 2164 & 2031 & 2.38 & 2.45 & -6.2 & -9.0 & 2.8 \\
\hline Nicaragua & 0.8 & 0.9 & 114 & 115 & 2.42 & 2.32 & 0.5 & 2.3 & -1.8 \\
\hline Panama & 0.5 & 0.6 & 53 & 56 & 1.96 & 1.80 & 5.1 & 13.4 & -8.3 \\
\hline Paraguay & 1.0 & 1.1 & 82 & 74 & 1.52 & 1.40 & -9.4 & 0.9 & -10.3 \\
\hline Peru & 4.4 & 4.2 & 465 & 490 & 2.07 & 2.27 & 5.4 & -4.9 & 10.3 \\
\hline Puerto Rico & 0.4 & 0.2 & 6 & 3 & 0.32 & 0.34 & -56.7 & -58.7 & 2.1 \\
\hline Uruguay & 0.4 & 0.4 & 13 & 16 & 0.71 & 0.93 & 23.1 & -6.7 & 29.8 \\
\hline
\end{tabular}


Table 2 Number of leukemia deaths in girls, age-standardised mortality rates and percentage change in cases due to population and risk, 2015 and 2030

\begin{tabular}{|c|c|c|c|c|c|c|c|c|c|}
\hline \multirow[t]{2}{*}{ Countries } & \multicolumn{2}{|c|}{ Population (per million) } & \multicolumn{2}{|c|}{ Number of new deaths } & \multicolumn{2}{|c|}{ Age-standardised mortality rates } & \multirow{2}{*}{$\begin{array}{l}\text { Total } \\
\text { change } \\
(\%)\end{array}$} & \multirow{2}{*}{$\begin{array}{l}\text { Change } \\
\text { due to } \\
\text { population } \\
\text { (\%) }\end{array}$} & \multirow{2}{*}{$\begin{array}{l}\text { Change } \\
\text { due to } \\
\text { risk (\%) }\end{array}$} \\
\hline & 2015 & 2030 & 2015 & 2030 & 2015 & 2030 & & & \\
\hline Argentina & 5.3 & 5.4 & 369 & 419 & 1.37 & 1.51 & 13.5 & 1.4 & 12.1 \\
\hline Brazil & 23.4 & 19.9 & 1370 & 1109 & 1.18 & 1.14 & -19.0 & -15.0 & -4.0 \\
\hline Chile & 1.8 & 1.6 & 103 & 98 & 1.16 & 1.22 & -4.9 & -9.4 & 4.6 \\
\hline Costa Rica & 0.5 & 0.4 & 41 & 32 & 1.51 & 1.29 & -22.2 & -7.6 & -14.5 \\
\hline Cuba & 0.9 & 0.8 & 55 & 49 & 1.23 & 1.28 & -11.3 & -14.5 & 3.3 \\
\hline Ecuador & 2.3 & 2.4 & 241 & 295 & 2.09 & 2.40 & 22.3 & 5.2 & 17.1 \\
\hline Guatemala & 2.9 & 3.1 & 211 & 206 & 1.43 & 1.35 & -2.6 & 4.3 & -6.9 \\
\hline Mexico & 17.2 & 15.5 & 1784 & 1545 & 2.05 & 1.99 & -13.4 & -9.5 & -3.8 \\
\hline Nicaragua & 0.8 & 0.9 & 96 & 141 & 2.14 & 2.91 & 47.1 & 3.1 & 43.9 \\
\hline Panama & 0.5 & 0.6 & 52 & 51 & 1.94 & 1.71 & -2.5 & 10.7 & -13.2 \\
\hline Paraguay & 0.9 & 1.0 & 62 & 51 & 1.29 & 1.05 & -17.3 & 6.6 & -23.8 \\
\hline Peru & 4.3 & 4.1 & 378 & 507 & 1.74 & 2.40 & 34.1 & -4.8 & 38.9 \\
\hline Puerto Rico & 0.3 & 0.1 & 5 & 3 & 0.34 & 0.42 & -40.0 & -53.1 & 13.1 \\
\hline Uruguay & 0.4 & 0.3 & 13 & 14 & 0.73 & 0.83 & 6.2 & -7.0 & 13.2 \\
\hline
\end{tabular}

wide range of mortality rates among LAC countries in the last 5 years of the study period (from 0.32 to 2.88 in boys and from 0.33 to 2.14 in girls).

Puerto Rico and Uruguay had significant downward trends in both sexes, along with the lowest mortality rates in the region. These outcomes are in line with the mortality trends worldwide [5, 9]. A study of southern and eastern European countries found a significant decrease in mortality rates of childhood leukemia [7]. Similarly, Bertuccio et al. [5] found downward leukemia mortality trends in the United States, Japan, and Western and Central European countries [5], which could be explained by the improvement of healthcare delivery and the development and implementation of novel treatment regimens $[5,27,28]$.

Mortality rates for childhood leukemia in many LAC countries remain higher than those in high-income countries $[11,29]$. Our study shows mortality rates up to 2.88 in boys and up to 2.14 in girls, whereas European countries report mortality rates up to 1.63 among boys and up to 1.35 among girls [5]. Another study in the United States estimated a mortality rate of 0.71 for both sexes from 2007 to 2010 [6]. Few countries in our analysis have mortality rates as low as those of the United States and European nations for both sexes. In the last 5 years of our study (2013-2017), Venezuela, Ecuador, and Nicaragua reported the highest mortality rates among boys and Nicaragua, Ecuador, and Mexico among girls. Previous studies also reported higher mortality rates for Mexico, Ecuador, and Venezuela than other LAC countries $[9,10]$. For this reason, it is necessary to identify risk factors for leukemia mortality in further research in these countries. Another relevant finding is the high mortality rates among children from Venezuela, which could be related to the country's socioeconomic and political instability in recent years [30], limiting the healthcare delivery to the pediatric population. Additionally, we only estimated mortality rates until 2014, due to a lack of national information on cancer deaths reports for the 2015-2017 period, restraining a proper comparison with the remaining LAC countries.

Important gaps remain in LAC countries to reduce the mortality of childhood leukemia, such as socioeconomic inequalities, low access to high-quality health care, delayed diagnosis, and limited access to novel treatment [29, 31-33]. Studies have shown a relationship between childhood leukemia and factors related to economic status, mainly in low-income African countries [29, 34], and that these economic disparities affect access to health services in certain communities within countries [32, 35]. However, childhood leukemia and economic status do not appear to be significantly related in high-income countries such as Switzerland or the US [31, 36], suggesting that others factors have contribute to leukemia mortality. For example, some reports found that abandonment of treatment is a major barrier to successful treatment and remission of the disease in low- and middle-income countries [14, 37, 38], which could increase the mortality rates in this population. 
Although these inequities are plausible explanations for the unremarkable trends seen in our analysis, there is still the need to explore further factors such as environmental hazard or components of the healthcare system, to generate tailored and evidencebased health policies.

The comparison between changes resulting from the increase in leukemia mortality and changes resulting from demographic population structure are notable. Ecuador and Argentina showed a higher risk of death for boys, and Nicaragua and Peru for girls. The predicted rates in Peru may not be attained however as, the World Health Organization chose Peru in 2018 as the Index Country to accomplish a $60 \%$ increase in survival of Pediatric Cancer in 2030 [39], where the Ministry of Health and stakeholders are committed to working toward that goal.

Possible problems related to the increased risk of leukemia mortality may be related to social inequalities and access to health systems as mentioned above [29, 31-33]. In addition, countries such as Puerto Rico had a decline in the mortality due to changes in population size and structure, even with an increased risk of leukemia mortality. The changes associated with the population structure may be related to factors that differ by country, such as a reduction in the birthrate. Studies that assess trends over time allow the creation and improvement of public policies aimed at a better structuring of the health system, based on predictions for the future. Moreover, they allow health planning, especially for the most vulnerable groups $[40,41]$.

A limitation of this study is the variability of the data records of each country and the lack of availability of data for some countries such as Honduras, Belize, and Bolivia. Secondly, we could not analyze incidence data given the lack of population-based cancer registries in most countries. Nevertheless, our study gives the most recent comprehensive epidemiological analysis of mortality patterns for childhood leukemia from LAC countries and provides a forecast to 2030, the target year by which WHO aims to improve childhood cancer survival to least $60 \%$. The results of this study should prompt further research in areas such as the relationship between socioeconomic status, healthcare delivery, or environmental hazard and mortality or incidence of childhood leukemia.

\section{Conclusions}

Overall, we found a wide variation in mortality trends among children under 15 years of age in most LAC countries. Furthermore, LAC nations should perform interventions to reduce socioeconomic inequalities and ensure universal healthcare coverage to prevent the increasing mortality rates projected by 2030 .

\section{Supplementary Information}

The online version contains supplementary material available at https://doi. org/10.1186/s12887-020-02408-y.

Additional file 1: Supplementary 1. Age-standardized mortality rates from leukemia in children from Latin America and the Caribbean in the periods 2000-2005, and 2012-2017, and corresponding percent changes.

Additional file 2: Supplementary 2. Estimated annual percent change (EAPC, \%) and 95\% confidence interval (Cl) for leukemia mortality rates in $0-14$ years.

\section{Abbreviations \\ ASMRs: Age-standardized mortality rates; LAC: Latin American and the Caribbean}

\section{Acknowledgements}

We would like to thank Dra. Rosdali Diaz and Dra. Liliana Vasquez for his willingness to discuss and review the study.

\section{Authors' contributions}

Conceived and designed the idea: JSTR, BV, PGC. Had full access to all the data in the study and take responsibility for the integrity of the data and the accuracy of the data analysis: JSTR, PGC, CAV,DLBS. Contributed to the writing of the manuscript: All authors. Contributed to the statistical analysis: JSTR, BV, PGC, CAV, IRB, DLBS. Critical revision of the manuscript: KAM, CL. Approval of the submitted and final version: All authors.

\section{Funding}

Self-funded.

Availability of data and materials

The datasets generated and/or analysed during the current study are available in the following link:

https://www.who.int/healthinfo/statistics/mortality_rawdata/en/

\section{Ethics approval and consent to participate}

Ethical approval and consent of the participant were not necessary since this study involved the use of a previously published secondary database.

Consent for publication

Not applicable.

\section{Competing interests}

The author(s) declare that they have no competing interests.

\section{Author details}

${ }^{1}$ Universidad Científica del Sur, Lima, Peru. ${ }^{2}$ Universidad Católica Los Ángeles de Chimbote, Instituto de Investigación, Chimbote, Peru. ${ }^{3}$ Latin American Network for Cancer Research (LAN-CANCER), Lima, Peru. ${ }^{4}$ Milken Institute School of Public Health, The George Washington University, Washington, DC, USA. ${ }^{5}$ Sociedad Científica San Fernando, Universidad Nacional Mayor de San Marcos, Lima, Peru. ${ }^{6}$ Graduate Program in Collective Health, Federal

University of Rio Grande do Norte, Natal, Rio Grande do Norte State, Brazil. ${ }^{7}$ Department of Clinical Sciences and Community Health, Università degli Studi di Milano, 20133 Milan, Italy. ${ }^{8}$ Division of Cancer Epidemiology and Genetics, National Cancer Institute, Bethesda, MD, USA. ${ }^{9}$ Research group on Methodology, Methods, Models and Outcomes of Health and Social Sciences (M3O), Faculty of Health Sciences and Welfare, Centre for Health and Social Care Research (CESS), University of Vic-Central University of Catalonia (UVic-UCC), Barcelona, Spain.

Received: 23 August 2020 Accepted: 28 October 2020

Published online: 07 November 2020

\section{References}

1. Miranda-Filho A, Piñeros M, Ferlay J, Soerjomataram I, Monnereau A, Bray F. Epidemiological patterns of leukaemia in 184 countries: a population-based study. Lancet Haematol. 2018;5(1):e14-24. 
2. Bray F, Ferlay J, Soerjomataram I, Siegel RL, Torre LA, Jemal A. Global cancer statistics 2018: GLOBOCAN estimates of incidence and mortality worldwide for 36 cancers in 185 countries. CA Cancer J Clin. 2018;68(6):394-424.

3. International Agency for Research on Cancer. Cancer Today [Internet]. WHO; 2018. Available from: https://gco.iarc.fr/today/home. Accessed 30 May 2020.

4. Bhatnagar N, Qureshi A, Hall G. Leukaemias: a review. Paediatr Child Health. 2017;27(11):489-94.

5. Bertuccio P, Bosetti C, Malvezzi M, Levi F, Chatenoud L, Negri E, et al. Trends in mortality from leukemia in Europe: an update to 2009 and a projection to 2012. Int J Cancer. 2013;132(2):427-36.

6. Smith MA, Altekruse SF, Adamson PC, Reaman GH, Seibel NL. Declining childhood and adolescent cancer mortality. Cancer. 2014;120(16):2497-506.

7. Petridou ET, Dimitrova N, Eser S, Kachanov D, Karakilinc H, Varfolomeeva S, et al. Childhood leukemia and lymphoma: time trends and factors affecting survival in five southern and eastern European Cancer registries. Cancer Causes Control. 2013;24(6):1111-8.

8. Malvezzi M, Carioli G, Bertuccio P, Rosso T, Boffetta P, Levi F, et al. European cancer mortality predictions for the year 2016 with focus on leukaemias. Ann Oncol. 2016;27(4):725-31.

9. Chatenoud L, Bertuccio P, Bosetti C, Levi F, Negri E, La Vecchia C. Childhood cancer mortality in America, Asia, and Oceania, 1970 through 2007. Cancer. 2010;116(21):5063-74.

10. Curado MP, Pontes T, Guerra-Yi ME, Cancela MC. Leukemia mortality trends among children, adolescents, and young adults in Latin America. Rev Panam Salud Publica. 2011;29:96-102.

11. Kehm RD, Spector LG, Poynter JN, Vock DM, Altekruse SF, Osypuk TL. Does socioeconomic status account for racial and ethnic disparities in childhood cancer survival? Cancer. 2018;124(20):4090-7.

12. Silva-Junior AL, Alves FS, Kerr MWA, Xabregas LA, Gama FM, Rodrigues MGA, et al. Acute lymphoid and myeloid leukemia in a Brazilian Amazon population: epidemiology and predictors of comorbidity and deaths. PLoS One. 2019;14(8):e0221518.

13. Vasquez L, Oscanoa M, Tello M, Tapia E, Maza I, Geronimo J. Factors associated with the latency to diagnosis of childhood cancer in Peru. Pediatric Blood Cancer. 2016;63(11):1959-65.

14. Vasquez L, Diaz R, Chavez S, Tarrillo F, Maza I, Hernandez E, et al. Factors associated with abandonment of therapy by children diagnosed with solid tumors in Peru. Pediatric Blood Cancer. 2018;65(6):e27007.

15. Team WER. Ebola virus disease in West Africa - the first 9 months of the epidemic and forward projections. N Engl J Med. 2014;2014(371):1481-95.

16. World Health Organization. International classification of disease and related health problems: 10th revision. Geneva: World Health Organization; 1992.

17. Pan American Health Organization. Population National Level. [ Cited March 20, 2020]. Available in: https://www.paho.org/data/index.php/en/indicators/ demographics-core/308-poblacion-nac-en.html.

18. Carioli G, La Vecchia C, Bertuccio P, Rodriguez T, Levi F, Boffetta P, et al. Cancer mortality predictions for 2017 in Latin America. Ann Oncol. 2017 28(9):2286-97.

19. Carioli G, Bertuccio P, Malvezzi M, Rodriguez T, Levi F, Boffetta P, et al. Cancer mortality predictions for 2019 in Latin America. Int J Cancer. 2020; 147(3):619-32.

20. World Health Organization. Age Standardization of Rates: A new Who Standard. 2011. Available from: http://www.who.int/healthinfo/paper31. pdf?ua=1. Accessed 7 June 2020.

21. National Cancer Institute. Joinpoint regression program. [Accesed 4 April, 2020] .Available in: https://surveillance.cancer.gov/help/joinpoint.

22. Kim HJ, Fay MP, Feuer EJ, Midthune DN. Permutation tests for joinpoint regression with applications to cancer rates. Stat Med. 2000;19(3):335-51.

23. Kim HJ, Fay MP, Yu B, Barrett MJ, Feuer EJ. Comparability of segmented line regression models. Biometrics. 2004;60(4):1005-14.

24. Barbosa IR, de Souza DL, Bernal MM, do CC Costa I. Cancer mortality in Brazil: temporal trends and predictions for the year 2030. Medicine. 2015; 94(16):e746.

25. Moller B, Fekjær H, Hakulinen T, Tryggvadóttir L, Storm HH, Talback M, et al. Prediction of cancer incidence in the Nordic countries up to the year 2020. Eur J Cancer. 2002;11:S1-96.

26. Møller B, Fekjær H, Hakulinen T, Sigvaldason H, Storm HH, Talbäck M, et al. Prediction of cancer incidence in the Nordic countries: empirical comparison of different approaches. Stat Med. 2003;22(17):2751-66.

27. Jakab Z, Juhasz A, Nagy C, Schuler D, Garami M. Hungarian Paediatric Haemato-Oncology N. Trends and territorial inequalities of incidence and survival of childhood leukaemia and their relations to socioeconomic status in Hungary, 1971-2015. Eur J Cancer Prev. 2017;26:S183-S90 Joining forces for better cancer registration in Europe.

28. Marcos-Gragera R, Galceran J, Martos C, de Munain A, Vicente-Raneda M, Navarro C, et al. Incidence and survival time trends for Spanish children and adolescents with leukaemia from 1983 to 2007. Clin Transl Oncol. 2017; 19(3):301-16.

29. Force LM, Abdollahpour I, Advani SM, Agius D, Ahmadian E, Alahdab F, et al. The global burden of childhood and adolescent cancer in 2017: an analysis of the global burden of disease study 2017. Lancet Oncol. 2019; 20(9):1211-25

30. Page KR, Doocy S, Ganteaume FR, Castro JS, Spiegel P, Beyrer C. Venezuela's public health crisis: a regional emergency. Lancet. 2019;393(10177):1254-60.

31. Poole C, Greenland S, Luetters C, Kelsey JL, Mezei G. Socioeconomic status and childhood leukaemia: a review. Int J Epidemiol. 2006;35(2):370-84.

32. Magrath I, Steliarova-Foucher E, Epelman S, Ribeiro RC, Harif M, Li C-K, et al. Paediatric cancer in low-income and middle-income countries. Lancet Oncol. 2013;14(3):e104-e16.

33. Escamilla-Santiago RA, Narro-Robles J, Fajardo-Gutiérrez A, Rascón-Pacheco RA, López-Cervantes M. Tendencia de la mortalidad por cáncer en niños y adolescentes según grado de marginación en México (1990-2009). Salud Publ Mex. 2012:54(6):587-94.

34. Hashemizadeh $H$, Boroumand $H$, Noori R, Darabian M. Socioeconomic status and other characteristics in childhood leukemia. Iran J Ped Hematol Oncol. 2013;3(1):182.

35. Dávila-Cervantes CA, Agudelo-Botero M. Health inequalities in Latin America: persistent gaps in life expectancy. Lancet Planetary Health. 2019; 3(12):e492-e3.

36. Adam M, Kuehni CE, Spoerri A, Schmidlin K, Gumy-Pause F, Brazzola P, et al. Socioeconomic status and childhood leukemia incidence in Switzerland. Front Oncol. 2015:5:139

37. Seah T, Zhang C, Halbert J, Prabha S, Gupta S. The magnitude and predictors of therapy abandonment in pediatric central nervous system tumors in low-and middle-income countries: systematic review and metaanalysis. Pediatr Blood Cancer. 2019;66(6):e27692.

38. Navarrete M, Rossi E, Brivio E, Carrillo J, Bonilla M, Vasquez R, et al. Treatment of childhood acute lymphoblastic leukemia in Central America: a lower-middle income countries experience. Pediatr Blood Cancer. 2014; 61(5):803-9.

39. World Health Organization. WHO Global Initiative for Childhood Cancer: progress on all fronts. [Cited 15 June, 2020]. Available in: https://www.who. int/news-room/detail/14-02-2020-who-global-initiative-for-childhood-cancerprogress-on-all-fronts.

40. Marinho F, de Azeredo Passos VM, Malta DC, França EB, Abreu DM, Araújo VE, et al. Burden of disease in Brazil, 1990-2016: a systematic subnational analysis for the global burden of disease study 2016. Lancet. 2018; 392(10149):760-75.

41. MdFMd S, Malta DC, França EB, Barreto ML. Changes in health and disease in Brazil and its states in the 30 years since the unified healthcare system (SUS) was created. Cienc Saude Colet. 2018;23:1737-50.

\section{Publisher's Note}

Springer Nature remains neutral with regard to jurisdictional claims in published maps and institutional affiliations.

Ready to submit your research? Choose BMC and benefit from:

- fast, convenient online submission

- thorough peer review by experienced researchers in your field

- rapid publication on acceptance

- support for research data, including large and complex data types

- gold Open Access which fosters wider collaboration and increased citations

- maximum visibility for your research: over $100 \mathrm{M}$ website views per year

At $\mathrm{BMC}$, research is always in progress.

Learn more biomedcentral.com/submissions 